\title{
The Status of Glutathione Peroxidase, Superoxide Dismutase, Vitamins A, C, E and Malondialdehyde in Patients with Cardiovascular Disease in Zahedan, Southeast Iran
}

\author{
Mansour KARAJIBANI ${ }^{1, *}$, Mohammad HASHEMI ${ }^{2, * *, * * *}$, Farzaneh MoNTAZERIFAR ${ }^{1, *}$, \\ Ahmad BoLOURI ${ }^{3}$ and Madhurima DIKSHIT ${ }^{4, * * *}$ \\ ${ }^{1}$ Department of Nutrition, ${ }^{2}$ Department of Clinical Biochemistry, ${ }^{3}$ Department of Cardiovascular Disease, \\ School of Medicine, Zahedan University of Medical Sciences, Zahedan, Iran \\ ${ }^{4}$ Division of Biochemistry, Department of Chemistry, Pune University, Pune-411007, India
}

(Received March 15, 2009)

\begin{abstract}
Summary Growing evidence has demonstrated that oxidative stress and increased altered oxygen utilization contribute to atherogenesis and cardiovascular disease (CVD) progression. Antioxidants protect the body from damage caused by free radicals. The objective of this study was to determine antioxidants status in CVD patients. This cross-sectional study was performed on 71 patients clinically diagnosed with CVD and 63 healthy individuals. Plasma malondialdehyde (MDA) level was measured for lipid peroxidation product and erythrocyte SOD and GPx activities as enzymatic antioxidants. The serum levels of vitamins $\mathrm{A}$ and $\mathrm{E}$ were assayed using HPLC and vitamin $\mathrm{C}$ by the photometric method. Total antioxidant capacity (TAC) was measured using the ferric reducing ability of plasma (FRAP) method. The results showed a significant reduction in antioxidant status (enzymatic and non-enzymatic) with a concomitant increase in the concentrations of lipid peroxidation products in CVD patients. There was a significant inverse correlation among TAC, SOD, GPx and vitamin $\mathrm{C}$ with MDA. It can be concluded that the antioxidant defense system plays an important role in preventing the development and progression of CVD with the ability to control oxidative stress.
\end{abstract}

Key Words oxidative stress, antioxidant status, lipid peroxidation, CVD patients

Cardiovascular disease (CVD), especially coronary artery disease $(\mathrm{CAD})$, is responsible for the highest mortality rate in Iran $(1,2)$. It accounts for nearly $50 \%$ of all deaths each year (3). Oxidation of biomolecules may play a role in susceptibility to a great number of diseases (4). There is suggestive evidence that oxidative stress plays a role in the pathophysiology of several major cardiovascular diseases: atherosclerosis, hypertension, heart failure, stroke, coronary heart disease (CHD), myocardial infarction (MI), ischemic heart disease and diabetes $(5,6)$. Several sources of oxygen/ nitrogen species occur in CVD. Reactive oxygen species (ROS) and nitrogen-derived free radicals or reactive nitrogen species (RNS) are the several products of oxidation-reduction reactions. Both ROS and RNS are causes of atherogensis $(5,7)$. The formation of ROS exerts oxidative stress on the myocardium that may cause heart failure (8). Oxidative stress is caused by the presence of free radicals or radical-generating agents in concentrations that overwhelm natural radical-blocking or scavenging mechanisms (4). The most plausible and biologically relevant modification of LDL is oxidation. In the early phase, mild oxidation of LDL results in

\footnotetext{
* Present address: Pune University, Pune-411007, India.

** To whom correspondence should be addressed.

*** Both authors share senior authorship.

E-mail: mhd.hashemi@gmail.com
}

the formation of minimally modified $\operatorname{LDL}(5,7,9)$. Oxidized LDL (ox-LDL) not only causes formation of the fatty streak but also, along with a host of other physical and humoral mediators, damages the endothelium (7, $10,11)$. The damaged endothelium allows for continued transport of inflammatory cells and mediators into vessel walls and this process generates ROS (11). To combat oxidative stress, the cells have evolved both enzymatic and non-enzymatic mechanisms to protect against the toxic effects of oxidants $(12,13)$. Enzymatic mechanisms include superoxidase dismutase (SOD), catalase and glutathione peroxidase (GPx); the nonenzymatic antioxidants include glutathione (GSH), ubiquinone, flavonoids, alpha-tocopherol, retionol and other carotenoids $(14,15)$.

Under normal condition, both types of mechanisms operate together to maintain homeostasis. However, under pathophysiological conditions ROS production exceeds the scavenging capacity of cellular antioxidant systems and the resultant oxidative stress can damage the lipids in cell membranes, protein and DNA of the cell (11-13). The biological oxidative effects of free radicals are controlled by a spectrum of antioxidants: SOD and GPx which nature has provided to neutralize the free radicals (7). The first line in enzymatic antioxidants is SOD, which catalyses dismutation of the superoxide anion into $\mathrm{H}_{2} \mathrm{O}_{2}$, which is then converted to $\mathrm{H}_{2} \mathrm{O}$ by catalase (CAT) and GPx in synergy with GSH. GPx can also 
reduce organic peroxides into their corresponding alcohols. GPx uses GSH as a hydrogen donor whereby GSH is oxidized (16).

The endogenous antioxidant systems endow tissue with substantial ability to balance the ROS effect under normoxic conditions (8). Depleted antioxidant defenses can lead to oxidative stress, that is, imbalance between the rates of production and elimination of free radicals, increasing the likelihood of damage to other molecules (13). Vitamin $\mathrm{C}$ is the major water-soluble antioxidant vitamin (10). It prevents oxidative modification of LDL primarily by scavenging free radicals and other reactive species, thereby preventing them from interacting with LDL (17). Moreover, vitamin C preserves vitamin E and $\beta$-carotene levels during oxidative stress in vitro. It has demonstrated synergistic activity with vitamin $\mathrm{E}$ in protecting LDL from oxidation (18). Vitamin E could influence the enzymatic antioxidants in addition to its function as a free radical scavenger (16). It also acts as a chain-breaking antioxidant for LDL lipid. In vitro studies have shown that this process does not begin until oxidative stress depletes the host vitamin content (19). Vitamin E seems to have the most cardioprotective potential of all the antioxidants. In vitro studies suggest that a combination of antioxidants will provide the most benefit (20). $\beta$-carotene such as $\alpha$-tocopherol inhibits LDL oxidation and might have an important role in the prevention of atherosclerosis (21).

The aim of the present study was to investigate biomarkers which may have an important role in the pathophysiology of CVD, such as oxidative stress molecules; malondialdehyde (MDA), antioxidant enzymes; SOD and GPx and non-enzymatic antioxidants; vitamins $\mathrm{A}, \mathrm{E}$ and $\mathrm{C}$ and total antioxidant capacity.

\section{MATERIALS AND METHODS}

Patients and healthy subjects. Seventy-one patients with CVD (29 male; 42 female) and 63 healthy subjects (22 male; 41 female) were enrolled in the study from December 2006 to September 2007. The diagnosis of CVD patients, admitted to the intensive cardiac care unit (CCU and Post-CCU) wards at Khatam-Al-Anbia Hospital of Zahedan University of Medical Sciences, was established according to clinical criteria (unstable angina, chest pain which lasted for up to the $3 \mathrm{~h}$ ), echocardiography changes and total $\mathrm{CK}$ and $\mathrm{CK}_{\mathrm{MB}}$ activity. The control group consisted of 63 age- and sexmatched healthy subjects with normal electrocardiograph and without any history of hypertension, heart disease, diabetes mellitus, renal or liver diseases, malignancy, endocrine disorders, pregnancy, operations or any acute medical conditions in the 3 mo prior to the study. Neither group received antioxidant therapies or vitamin supplements. The study protocol was approved by the ethical committee of Zahedan University of Medical Sciences and informed consent was obtained from all patients and healthy individuals.

Blood sampling. Blood samples were collected in different tubes after overnight fasting. Heparinized tubes were used for measurement of erythrocyte SOD and
GPx. Plasma was used for determination of vitamin C, MDA and serum was used for vitamins $A$ and $E$.

Malondialdehyde (MDA) assay. Lipid peroxidation in the plasma was evaluated by the spectrophotometric method based on the reaction between MDA and thiobarbituric acid (TBARS) (22). Briefly, to $0.5 \mathrm{~mL}$ plasma, $2.5 \mathrm{~mL}$ of $20 \%$ tricholoroacetic (TCA) in $2 \mathrm{M}$ sodium sulfate was added. After precipitating the protein with TCA and washing with $0.05 \mathrm{M}$ sulfuric acid, it was incubated in a boiling water bath for $30 \mathrm{~min}$. After cooling, the samples were extracted with $n$-butanol and centrifuged at $3,500 \mathrm{rpm}$. The absorbance of samples was determined at $530 \mathrm{~nm}$. 1,1,3,3-Tetraethoxypropane was used as a standard. Concentration of MDA was expressed as micromoles of malondialdehyde per liter of plasma.

Superoxide dismutase (SOD) activity. SOD activity was determined based on the production of $\mathrm{O}_{2}{ }^{-}$anions by the xantine/xantine oxidase system (23) using a commercial assay kit (Randox, UK). The specific activity of SOD was expressed in units per gram of hemoglobin (U/g Hb).

Glutathione peroxidase (GPx) activity. GPx activity was measured using a commercial test kit (Randox) in heparinized whole blood by the procedure of Paglia and Valentine (24). Briefly, GPx catalyses the oxidation of glutathione (GSH) by cumene hydroperoxide. In the presence of glutathione reductase (GR) and NADPH, the oxidized glutathione (GSSG) is immediately converted to the reduced form with a concomitant oxidation of NADPH to $\mathrm{NADP}^{+}$. The decrease in absorbance at $340 \mathrm{~nm}$ was measured by spectrophotometer. The specific activity for GSH-Px was expressed in units per gram hemoglobin $(\mathrm{U} / \mathrm{g} \mathrm{Hb})$.

Vitamins $A$ and $E$ assay. Serum vitamins $A$ and $E$ were extracted with hexane and measured by using high pressure liquid chromatography (HPLC) in absorption at 325 and $292 \mathrm{~nm}$, respectively (25). Briefly, $500 \mu \mathrm{L}$ of serum was added to mixture of retinol acetate $(50 \mu \mathrm{L})$ and ethanol $(1,000 \mu \mathrm{L})$. Then, $1,500 \mu \mathrm{L}$ hexane was added and centrifuged for $2 \mathrm{~min}$ at $1,500 \mathrm{rpm}$. The upper layer was transferred into another tube. Hexane phase was evaporated in a heating block by using Nitrogen at $40^{\circ} \mathrm{C}$ and remain solved in $500 \mu \mathrm{L}$ mixture of methanol and di-ethylether. Then, $20 \mu \mathrm{L}$ of this solution was injected to the column of HPLC (Young Lin, South Korea). The analytical column: Nova pack C18, pressure: 2,600-3,000, run time: $8 \mathrm{~min}$, retention time: $1.3 \mathrm{~min}$ for vitamin $\mathrm{A}$ and $3.2 \mathrm{~min}$ for vitamin $\mathrm{E}$, and flow rate of $1.5 \mathrm{~mL} / \mathrm{min}$ was used.

Vitamin C assay. Total plasma vitamin C concentration $(\mathrm{mg} / \mathrm{dL})$ was measured by the photometric method. Ascorbic acid in plasma was oxidized by $\mathrm{Cu}^{2+}$ to form dehydroascorbic acid, which reacts with acidic 2,4-dinitrophenylhydrazine to form a red bis-hydrazone, which was measured at $520 \mathrm{~nm}$ (25). To $200 \mu \mathrm{L}$ of plasma $1 \mathrm{~mL}$ of freshly prepared methaphosphoric acid was added and centrifuged for $10 \mathrm{~min}$ at $2,500 \mathrm{rpm}$. Two hundred microliters of dinitrophenylhydrazine-thio- 
Table 1. General characteristics and lipid profiles of study groups.

\begin{tabular}{lccc}
\multicolumn{1}{c}{ Parameters } & CVD patients & Control groups & $p$-value \\
\hline Age $(\mathrm{y})$ & $56.7 \pm 11.1$ & $56.4 \pm 11.3$ & NS $^{1}$ \\
BMI $\left(\mathrm{kg} / \mathrm{m}^{2}\right)$ & $26.8 \pm 4.7$ & $26.5 \pm 4.6$ & NS \\
Sex & & & NS \\
$\quad$ Male & $29 / 71$ & $22 / 63$ & NS \\
$\quad$ Female & $42 / 71$ & $41 / 63$ & $p<0.0001$ \\
Blood pressure (mmHg) & & & $p<0.0001$ \\
$\quad$ Systolic & $145.6 \pm 16.3$ & $113.1 \pm 12.6$ & $p<0.0001$ \\
$\quad$ Diastolic & $93.1 \pm 13.2$ & $72.6 \pm 9.4$ & $p<0.0001$ \\
Total cholesterol (mg/dL) & $222 \pm 42.4$ & $180.2 \pm 29.3$ & $p<0.0001$ \\
Triglyceride (mg/dL) & $160.5 \pm 76.8$ & $114.3 \pm 45.1$ & $p<0.0001$ \\
LDL-C (mg/dL) & $146 \pm 48.2$ & $99.4 \pm 27.2$ & $57 \pm 12.6$ \\
HDL-C (mg/dL) & $43.8 \pm 11.9$ & & \\
\hline
\end{tabular}

Values are expressed as mean \pm SD.

${ }^{1}$ NS: not significant.

Table 2. Comparison of the levels of malondialdehyde (MDA), total antioxidant capacity (TAC), glutathione peroxides (GPx), superoxide dismutase (SOD) and vitamins A, E and C between CVD patients and healthy subjects.

\begin{tabular}{lccc}
\hline & CVD patients & Control & $p$ value \\
\hline Malondialdehyde $(\mu \mathrm{mol} / \mathrm{L})$ & $0.206 \pm 0.03$ & $0.116 \pm 0.02$ & $<0.0001$ \\
Total antioxidant capacity $(\mu \mathrm{mol} / \mathrm{L})$ & $538.2 \pm 118.8$ & $789.4 \pm 158.5$ & $<0.0001$ \\
Glutathione peroxides $(\mathrm{U} / \mathrm{g} \mathrm{Hb})$ & $14.3 \pm 4$ & $30.7 \pm 7.7$ & $<0.0001$ \\
Superoxidase dismutase $(\mathrm{U} / \mathrm{g} \mathrm{Hb})$ & $925.1 \pm 235$ & $2,273.5 \pm 552.2$ & $<0.0001$ \\
Vitamin A $(\mu \mathrm{g} / \mathrm{dL})$ & $53.4 \pm 14$ & $60.4 \pm 12.8$ & 0.022 \\
Vitamin $\mathrm{E}(\mu \mathrm{g} / \mathrm{dL})$ & $468.1 \pm 112.4$ & $696.2 \pm 169.5$ & $<0.0001$ \\
Vitamin $\mathrm{C}(\mathrm{mg} / \mathrm{dL})$ & $0.65 \pm 0.22$ & $1.2 \pm 0.4$ & $<0.0001$ \\
\hline
\end{tabular}

urea-copper sulfate (DTCS) reagent was added to $500 \mu \mathrm{L}$ of the clear supernatant, standard and blank. The tubes were incubated in a water bath at $37^{\circ} \mathrm{C}$ for $3 \mathrm{~h}$. After cooling $2 \mathrm{~mL}$ of cold sulfuric acid $(12 \mathrm{~mol} / \mathrm{L})$ was added. The absorbance at $520 \mathrm{~nm}$ was determined against the blank.

Total antioxidant capacity. Total antioxidant capacity (TAC) of plasma was measured by the ferric reducing ability of plasma (FRAP) assay (26). At low $\mathrm{pH}$ ferric tripyridyltriazine ( $\left.\mathrm{Fe}^{+3}-\mathrm{TPTZ}\right)$ complex is reduced to the ferrous $\left(\mathrm{Fe}^{+2}\right)$ form; an intensive blue color with an absorption maximum at $593 \mathrm{~nm}$ develops. The reaction was monitored for $4 \mathrm{~min}$. Aqueous solutions of known $\mathrm{Fe}^{+2}$ concentrations in the range of $100-1,000 \mu \mathrm{mol} / \mathrm{L}$ were used for calibration.

Lipid profiles assay. Serum total cholesterol, triglycerides and HDL-C were assessed by enzymatic methods using commercially available kits (27). LDL-C was estimated by the Friedewald formula (LDL-C $=$ total cholesterol-(HDL-C+triglycerides/5)) and VLDL-C calculated by: triglycerides/ 5 .

Statistical analysis. Results are expressed as means \pm SD. Statistical analysis was performed using SPSS 11.5 software. Unpaired t-test and Pearson's correlation coefficient were used to compare the groups and relationship between variables, respectively. The difference was considered significant at $p$-values less than 0.05.

\section{RESULTS}

Demographic and clinical characteristics of CVD patients and control groups are shown in Table 1. There were no significant differences in age, sex or BMI between case and control groups ( $p>0.05)$. Blood pressure and the concentrations of total cholesterol, triglyceride and LDL-C were found to be significantly increased in CVD patients compared to the control group $(p<0.0001)$, whereas the level of HDL-C decreased $(p<0.0001)$ (Table 1). As shown in Table 2, lipid peroxidation assessed in terms of plasma MDA levels was found higher in CVD patients than the control group $(0.206 \pm 0.03$ vs. $0.116 \pm 0.02 \mu \mathrm{mol} / \mathrm{L}) \quad(p<0.0001)$, whereas FRAP value (total antioxidant capacity) was lower $(538.2 \pm 118.8$ vs. $789.4 \pm 158.5 \mu \mathrm{mol} / \mathrm{L})(p<$ $0.0001)$. The results showed that the levels of glutathione peroxidase (GPx), superoxide dismutase (SOD) and vitamins $A, E$ and $C$ values were significantly lower in CVD patients than normal subjects (Table 2).

We found that there was a significantly negative correlation between MDA and GPx $(r=-0.362, p=0.001)$ (Fig. 1A), MDA and SOD $(r=-0.269, p=0.023)$ (Fig. 1B), MDA and vitamin C $(r=-0.392, p=0.000)$ (Fig. 1C), MDA and TAC $(r=-0.316, p=0.007)$ (Fig. 1D), and MDA and HDL-C $(r=-0.307, p=0.009)$ (Fig. 1E).

As shown in Fig. 2, There were significantly positive correlations between SOD and vitamin C $(r=0.261$, 

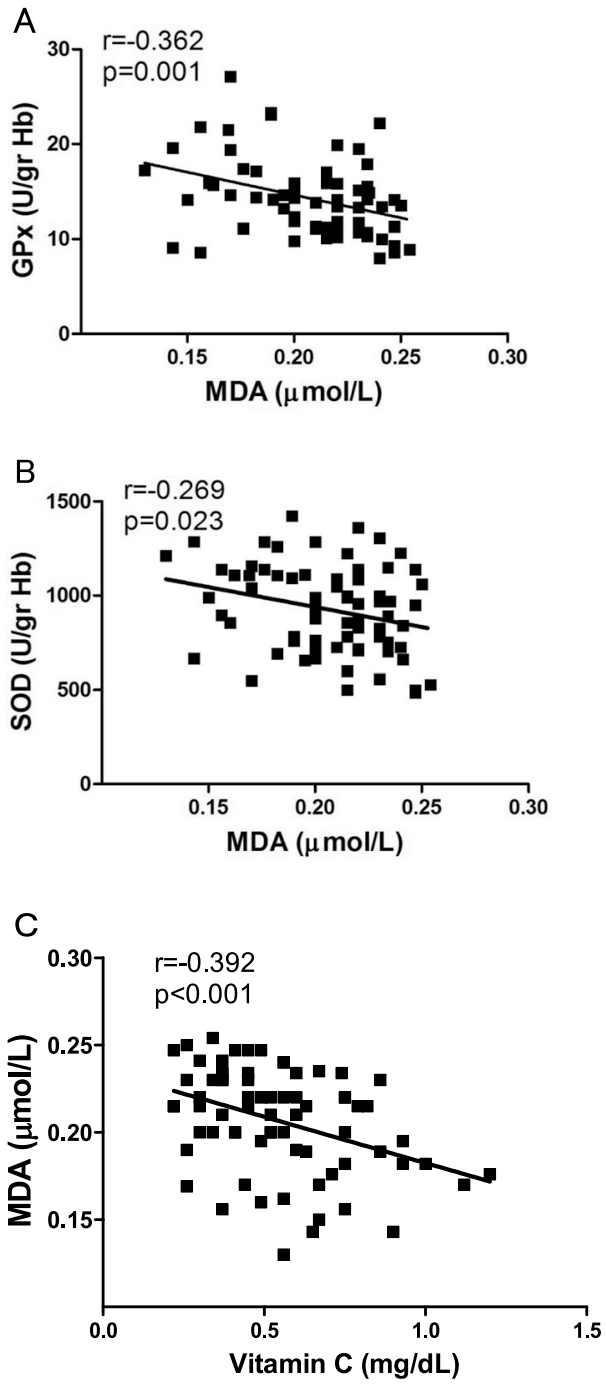

$p=0.027$ ) (Fig. 2A), vitamin $\mathrm{A}$ and vitamin $\mathrm{E}$ $(r=0.419, p=0.000)$ (Fig. 2B), GPx and vitamin $\mathrm{E}$ $(r=0.247, p=0.037)$ (Fig. 2C), GPx and vitamin C $(r=0.292, p=0.013)$ (Fig. 2D), and total antioxidant capacity and HDL-C ( $r=0.243, p=0.041)$ (Fig. 2E).

We also found that there was no statistically significant correlation between MDA and vitamin A $(r=-0.150, \quad p=0.210), \quad \mathrm{MDA}$ and vitamin $\mathrm{E}$ $(r=-0.212, p=0.075)$, SOD and GPx $(r=0.103$, $p=0.392)$, SOD and vitamin $\mathrm{E}(r=-0.065, p=0.587)$, vitamin $\mathrm{C}$ and vitamin $\mathrm{E}(r=0.207, r=0.083)$, vitamin $\mathrm{C}$ and vitamin A $(r=0.133, p=0.268)$, SOD and vita$\min \mathrm{A}(r=-0.010, p=0.934)$, or GPx and vitamin A $(r=0.201, p=0.092)$.

\section{DISCUSSION}

CVD is a leading cause of global mortality, accounting for almost 17 million deaths annually. Nearly $80 \%$ of this global mortality and disease burden occurs in developing countries (28). In this work, we revealed the differences in the levels of oxidant and antioxidant markers between CVD patients and healthy persons. Significant increase in MDA levels a lipid peroxidation products, and decrease in total antioxidant capacity indicate elevated oxidative stress in CVD patients. Simi-
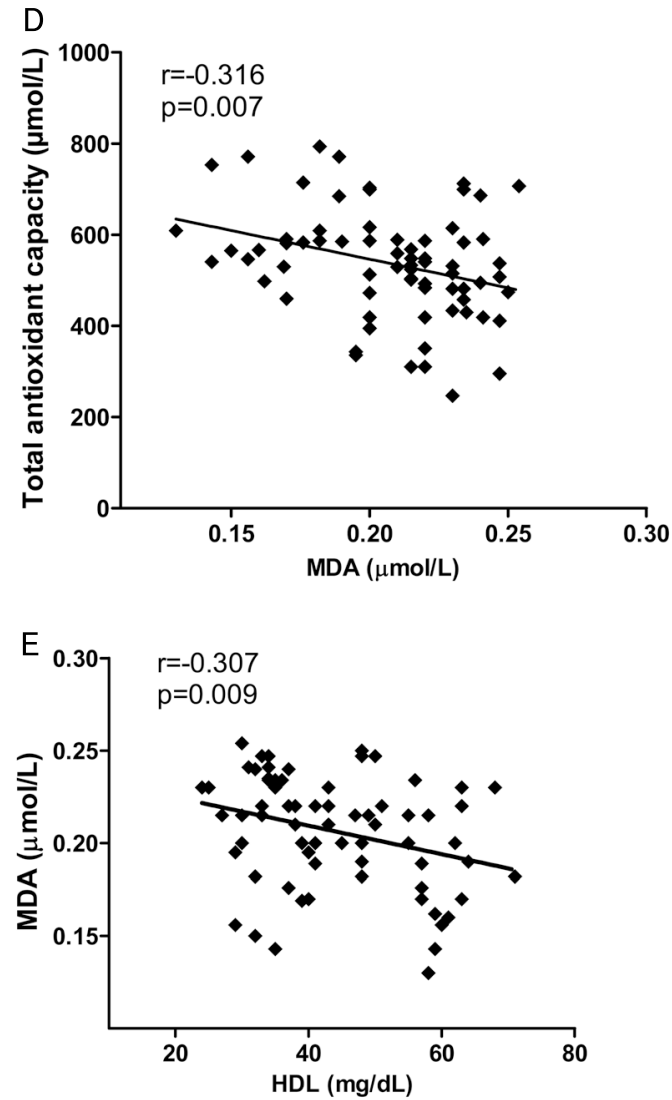

Fig. 1. Significantly negative correlation between MDA and GPx (A), MDA and SOD (B), MDA and Vit $\mathrm{C}(\mathrm{C}), \mathrm{MDA}$ and TAC (D), and MDA and HDL-C (E).

larly, Serdar et al. (23), McMurray et al. (29) and Polidori et al. (30) observed an increase in MDA level in patients with coronary artery disease (CAD), chronic heart failure (CHF) and congestive heart failure respectively. Several mechanisms are likely to be involved, including transition metal ion mediated generation of hydroxyl radicals, the production of ROS by the enzymes lipoxygenase and myeloperoxidase, and direct modification by reactive nitrogen species (5). These vitamins, particularly A and E, are components of LDL; hence one might expect that the differences in the susceptibility of individual LDL preparation to oxidation are largely dictated by variations in the amounts of the various antioxidants that are present in these samples. It is possible that differences in the incidence of heart disease are at least partly dependent on differences in the dietary intake and associated lipoprotein content of lipid-soluble antioxidants such as vitamin E (19). The oxidative modified LDL particles do not bind readily to the endogenous LDL receptor and are therefore not cleared from the circulation by this mechanism. They penetrate into the arterial intima more easily, are more readily oxidized, possibly because they contain less antioxidant protection, and are taken up by the macrophage scavenger receptors accelerating foam-cell for- 

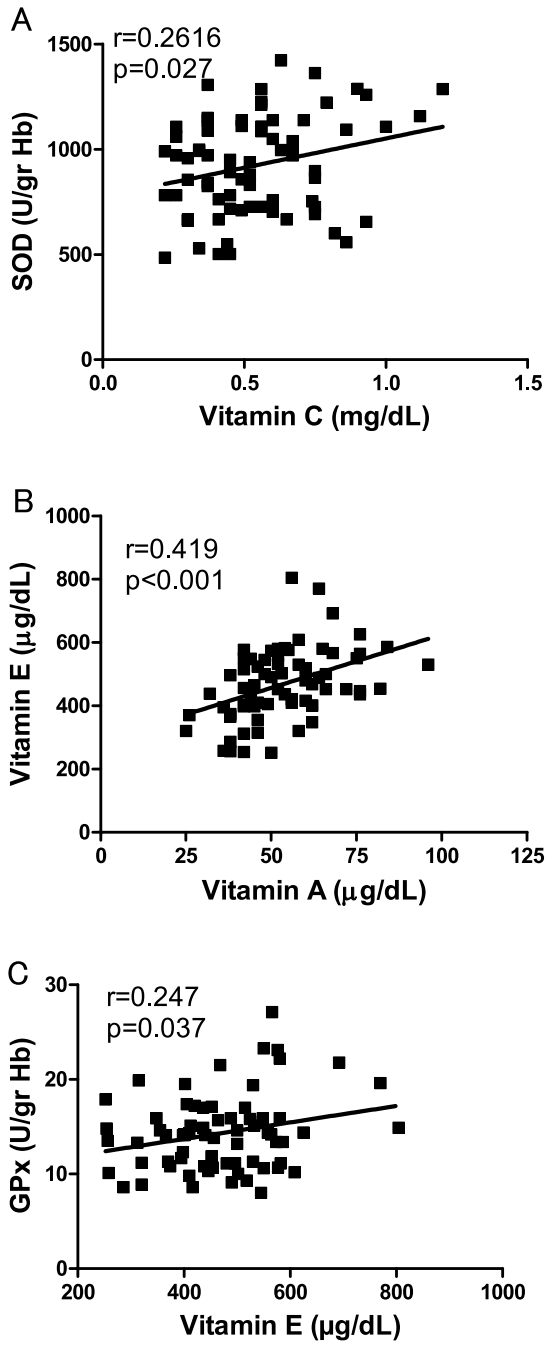

mation (21).

The results showed that the decrease in the activity of the SOD in erythrocytes was in parallel to the increase of lipid peroxidation. This decrease in SOD activity may be due to the effect of increased oxygen-derived free radicals on SOD. Sozmen et al. have also found decrease in SOD activity of patients with coronary heart disease in comparison with controls (31). McMurray et al. have shown an increase in reactive oxygen products (MDA, TBARS) to be directly proportional to levels of enzymatic antioxidant activities in CHF patients (29). The decrease in SOD activity seems to result from the effect of increased oxygen-derived free radicals. Thus, lower $\mathrm{O}_{2}{ }^{-}$concentrations induce the SOD activity while higher $\mathrm{O}_{2}{ }^{-}$concentrations inhibit it. Furthermore, catalase is activated in higher $\mathrm{H}_{2} \mathrm{O}_{2}$ concentrations whereas SOD is inhibited $(31,32)$. An inverse correlation was observed between SOD and MDA, while there was a direct correlation between SOD and vitamin C. Similarly, GPx levels were significantly decreased in CVD patients as compared to controls. That is consistent with the studies of Serdar et al. (23), Blankenberg et al. (33), Akkus et al. (34) and Yegin et al. (35). Oxygen-free radicals are generated particularly in the early stage of myocardial infarction and GSH is involved in the reduction of hydrogen peroxide radicals, resulting in
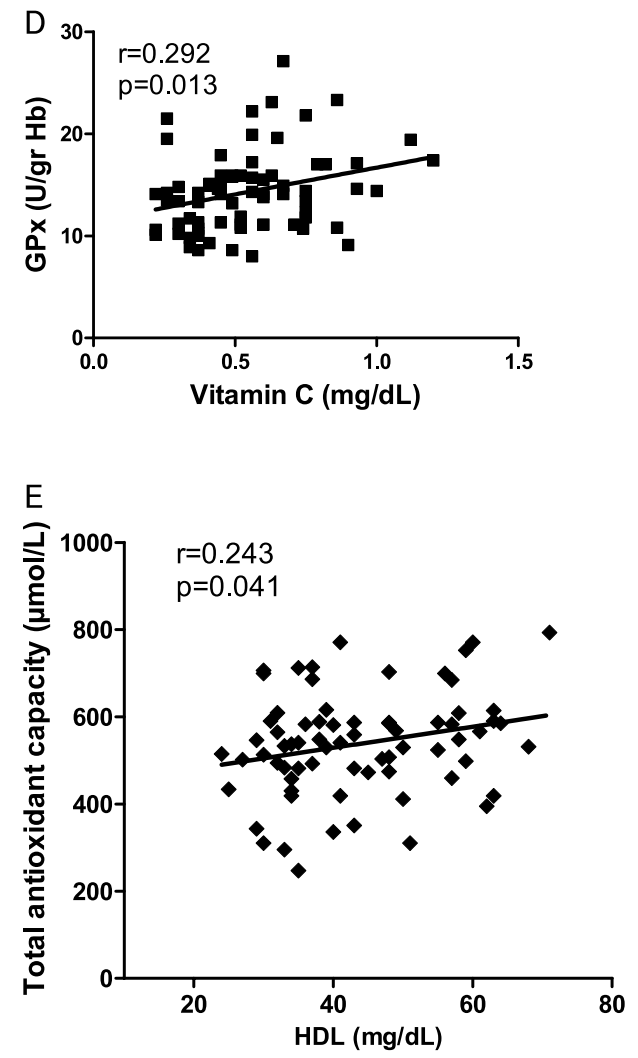

Fig. 2. Significantly positive correlation between SOD and Vit C (A), Vit A and Vit E (B), GPx and Vit E (C), GPx and Vit C (D), and TAC and HDL-C.

a decrease in GSH levels during that period (36). There was also significantly negative correlation between GPx and MDA, but with vitamins $\mathrm{E}$ and $\mathrm{C}$ it was positive. Our results showed that the decrease in the activity of the antioxidant enzyme was parallel to the increase of lipid peroxidation. Depressed GPx content may be associated with an enhanced protective mechanism against oxidative stress in CVD. In particular, the levels of non-enzymatic antioxidants such as, vitamins $A, E$ and $C$ had significantly decreased. Consistent with these findings, a number of studies demonstrated that there was a significant drop in vitamins $\mathrm{A}, \mathrm{E}$ and $\beta$-carotene in $\mathrm{CAD}$ and acute myocardial infarction (AMI) patients (23, 37). Many studies have investigated the mechanisms of the endogenous antioxidants in plasma and LDL inhibits lipid peroxidation and oxidation of LDL (38). Other studies have focused mainly on vitamins C, E and carotenoids. These vitamins protect cell membranes against free radical-mediated lipid oxidation and play a pivotal role in maintaining normal endothelial function (39). On the other hand, we observed significant inverse correlations between enzymatic and non-enzymatic antioxidants with oxidant parameters in CVD patients. This indicates severe damage to the antioxidant system, which is unable to combat oxidative stress. Antioxidants such as $\beta$-carotene, and vitamins $\mathrm{E}$ and $\mathrm{C}$ inhibit 
LDL oxidation (40). Besides, vitamin C deficiency as assessed by low plasma ascorbate concentration is a risk factor for coronary heart disease (CHD) (41). Vitamin $C$ is also important for maintaining levels of antioxidant vitamin $\mathrm{E}$ by reducing the vitamin $\mathrm{E}$ radical (the oxidized form of vitamin E). Thus, scavenger antioxidants are important not only because they react with free radicals directly, but also because they act synergistically with one another (19). Singh et al. showed that low plasma levels of vitamins $\mathrm{A}, \mathrm{E}, \mathrm{C}$ and $\beta$-carotene with high lipid peroxide levels were related to an increased risk of CAD. The decrease in serum antioxidant levels observed in the CVD patients is due to increased utilization of antioxidants because of the increased lipid oxidation (42).

Although the level of BMI did not differ between the study groups, according to the World Health Organization (WHO), 300 million in the world are clinically obese (43) and obesity is associated with oxidative stress, depletion of antioxidant reserves and oxidative modifications of plasma lipoproteins and lipids (44). On the other hand, a correlation between increasing BMI and enhanced systemic oxidative stress was observed $(7,45)$. After adjusting for factors such as age, sex, BMI and medical history in the two groups, it was observed that the blood pressure and levels of lipid profile of CVD patients were significantly higher than for the control group. Previous studies have suggested that hypertension may be related to increase oxidized LDL $(44,46)$. Although the mean value of blood pressure in the patients was almost acceptable, they were probably more at risk of oxidative stress because of various levels of blood pressure in CVD patients. Chrysohoou et al. found that pre-hypertension was associated with 15\% higher levels of oxidized LDL compared to normal blood pressure levels, after taking into account the potential confounding effect of various factors (44). Our results showed the increased levels of total cholesterol and triglyceride in CVD patients. At any rate, hypertriglyceridemia and hypercholesterolemia are associated with dyslipidimic which can develop into atherosclerosis (7). Ruel et al. showed abdominally obese dyslipidemic individuals are most likely to show high circulating concentrations of ox-LDL (13). On the other hand, the level of LDL-C increased in the CVD patients whereas HDL-C decreased. Although the levels of total cholesterol and triglyceride were more slightly of normal range in the CVD patients, according to the correlation between different lipid profiles and others factors in patients, it seems progress of CVD was increasing. Sozmen et al. have found an increase in total cholesterol, LDL-C and triglyceride level and decrease in HDL-C in patients with hypertension compared with a control group (31). The level of LDL oxidation varies. Thus ox-LDL consist of heterogenous numeral of modified lipid and protein molecules (17). Patients with atherosclerosis have an excessive increase in lipid peroxidation and the role of this uncontrolled lipid peroxidation in the pathogenesis of this disease has been reported (47). Smith et al. reported elevated levels of plasma LDL-C and triglycer- ide accompanied by reduced HDL-C levels is often associated with an increased risk of coronary heart disease (28). Oxidized LDL is associated with the pathogenesis of atherosclerosis, a key in the early stage of CVD. Nevertheless, oxidized LDL is toxic to vascular cells, and the cytotoxic potency of oxidized LDL has been linked to its content of lipid peroxidation products $(9,48)$.

The present results showed that the decrease in the activity of the total antioxidant capacity (TAC) in plasma was parallel to the increase of lipid peroxidation, which is consistent with a number of studies $(13,29)$. McMurray et al. (29) and Dubois-Randé et al. (49) similarly showed a decrease in antioxidant enzyme activities and increase in reaction oxygen products in patients with chronic heart failure and unstable angina, respectively. Although the antioxidant system (enzymatic/non-enzymatic) detoxifies ROS generated $(17,30)$, an imbalance between the factors and tendency of lipid profiles to increase in CVD patients can be enhanced by oxidative stress. It is a result of chronically elevated ROS and impaired antioxidant defense system (7) which is probably due to increased utilization of antioxidants because of increasing lipid peroxidation. Besides, the inverse relationship between lipid peroxidation and the antioxidant capacity of plasma in CVD patients is a key to elevated levels of ROS. Therefore, the present study supports oxidative stress as a causative factor for development of CVD.

To sum up, our results clearly showed that there was significant reduction in the antioxidant systems (enzymatic/non-enzymatic) with a concomitant increase in lipid peroxidation. Besides, we observed inverse correlations among GPx, SOD and vitamin C with MDA. Taken together, these results suggest that oxidative stress may affect the initiation and progression of atherogensis and plasma antioxidant status in CVD patients.

\section{Acknowledgments}

The authors would like to thank CCU/Post-CCU section staff in Zahedan Khatam-Al-Anbia Hospital for their kindly cooperation and the experts of the laboratory of National Nutrition and Food Technology Research Institute, Tehran, Iran and also the patients and healthy subjects who willingly participated in the study.

\section{REFERENCES}

1) Fazizi F, Esmaillzadeh A, Mirmiran FP. 2004. Obesity and cardiovascular disease risk factors in Tehran adults: a population-based study. East Mediterr Health J 10: 887-897.

2) Sarraf-Zadegan N, Sayed-Tabatabaei FA, Bashardoost N, Maleki A, Totonchi M, Habibi HR, Sotodehmaram E, Tafazoli F, Karimi A. 1999. The prevalence of coronary artery disease in an urban population in Isfahan, Iran. Acta Cardiol 54: 257-263.

3) Hatmi ZN, Tahvildari S, Gafarzadeh Motlag A, Sabouri Kashani A. 2007. Prevalence of coronary artery disease risk factors in Iran: a population based survey. BMC Cardiovasc Disord 7: 32.

4) Block G, Dietrich M, Norkus EP, Morrow JD, Hudes M, 
Caan B, Packer L. 2002. Factors associated with oxidative stress in human populations. Am J Epidemiol 156: 274-285.

5) Young IS, Woodside JV. 2001. Antioxidants in health and disease. J Clin Pathol 54: 176-186.

6) Heistad DD. 2006. Oxidative stress and vascular disease: 2005 Duff lecture. Arterioscler Thromb Vasc Biol 26: 689-695.

7) Singh U, Jialal I. 2006. Oxidative stress and atherosclerosis. Pathophysiology 13: 129-142.

8) Chen JK, Chow SE. 2005. Antioxidants and myocardial ischemia: reperfusion injuries. Chang Gung Med J 28: 369-377.

9) Diaz MN, Frei B, Vita JA, Keaney JF Jr. 1997. Antioxidants and atherosclerotic heart disease. $N$ Engl J Med 337: 408-416.

10) Jha P, Flather M, Lonn E, Farkouh M, Yusuf S. 1995. The antioxidant vitamins and cardiovascular disease. A critical review of epidemiologic and clinical trial data. Ann Intern Med 123: 860-872.

11) Madamanchi NR, Hakim ZS, Runge MS. 2005. Oxidative stress in atherogenesis and arterial thrombosis: the disconnect between cellular studies and clinical outcomes. J Thromb Haemost 3: 254-267.

12) Karmansky I, Shnaider H, Palant A, Gruener N. 1996. Plasma lipid oxidation and susceptibility of low-density lipoproteins to oxidation in male patients with stable coronary artery disease. Clin Biochem 29: 573-579.

13) Ruel G, Pomerleau S, Couture P, Lamarche B, Couillard C. 2005. Changes in plasma antioxidant capacity and oxidized low-density lipoprotein levels in men after short-term cranberry juice consumption. Metabolism 54: 856-861.

14) Aviram M. 2003. Lipid peroxidation and atherosclerosis: the importance of selected patient group analysis. Isr Med Assoc J 5: 734-735.

15) Urso ML, Clarkson PM. 2003. Oxidative stress, exercise, and antioxidant supplementation. Toxicology 189: 4154.

16) Cheng T, Zhu Z, Masuda S, Morcos NC. 2001. Effects of multinutrient supplementation on antioxidant defense systems in healthy human beings. J Nutr Biochem 12: 388-395.

17) Kaliora AC, Dedoussis GV, Schmidt H. 2006. Dietary antioxidants in preventing atherogenesis. Atherosclerosis 187: 1-17.

18) Reaven PD, Khouw A, Beltz WF, Parthasarathy S, Witztum JL. 1993. Effect of dietary antioxidant combinations in humans. Protection of LDL by vitamin E but not by beta-carotene. Arterioscler Thromb 13: 590-600.

19) Jessup W, Rankin SM, De Whalley CV, Hoult JR, Scott J, Leake DS. 1990. Alpha-tocopherol consumption during low-density-lipoprotein oxidation. Biochem J 265: 399405.

20) Nuttall SL, Kendall MJ, Martin U. 1999. Antioxidant therapy for the prevention of cardiovascular disease. QJM 92: 239-244.

21) Jialal I, Fuller CJ, Huet BA. 1995. The effect of alphatocopherol supplementation on LDL oxidation. A doseresponse study. Arterioscler Thromb Vasc Biol 15: 190198.

22) Satoh K. 1978. Serum lipid peroxide in cerebrovascular disorders determined by a new colorimetric method. Clin Chim Acta 90: 37-43.

23) Serdar Z, Aslan K, Dirican M, Sarandol E, Yesilbursa D,
Serdar A. 2006. Lipid and protein oxidation and antioxidant status in patients with angiographically proven coronary artery disease. Clin Biochem 39: 794-803.

24) Paglia DE, Valentine WN. 1967. Studies on the quantitative and qualitative characterization of erythrocyte glutathione peroxidase. J Lab Clin Med 70: 158-169.

25) Burtis CA, Ashwood ER. 2006. Tietz Textbook of Clinical Chemistry and Molecular Diagnostics, 14th ed, p 1079-1087, 1023-1025, 2302. Elsevier Saunders, Missouri.

26) Benzie IF, Strain JJ. 1996. The ferric reducing ability of plasma (FRAP) as a measure of "antioxidant power": the FRAP assay. Anal Biochem 239: 70-76.

27) Hashemi M, Daliri M, Mehrabifar H, Naderi M, Niazi A, Ghavami S. 2009. Lipid profile in patients with psoriasis in Zahedan, south-east Iran. J Eur Acad Dermatol Venereol 23: 461-462.

28) Smith SC Jr, Jackson R, Pearson TA, Fuster V, Yusuf S, Faergeman O, Wood DA, Alderman M, Horgan J, Home P, Hunn M, Grundy SM. 2004. Principles for national and regional guidelines on cardiovascular disease prevention: a scientific statement from the World Heart and Stroke Forum. Circulation 109: 3112-3121.

29) McMurray J, Chopra M, Abdullah I, Smith WE, Dargie HJ. 1993. Evidence of oxidative stress in chronic heart failure in humans. Eur Heart J 14: 1493-1498.

30) Polidori MC, Savino K, Alunni G, Freddio M, Senin U, Sies H, Stahl W, Mecocci P. 2002. Plasma lipophilic antioxidants and malondialdehyde in congestive heart failure patients: relationship to disease severity. Free Radic Biol Med 32: 148-152.

31) Sozmen B, Kazaz C, Taskiran D, Alan L, Akyol A, Sozmen EY. 1998. Plasma antioxidant status and nitrate levels in patients with hypertension and coronary heart disease. Tr J Med Sci 28: 525-531.

32) Freeman BA, Crapo JD. 1982. Biology of disease: free radicals and tissue injury. Lab Invest 47: 412-426.

33) Blankenberg S, Rupprecht HJ, Bickel C, Torzewski M, Hafner G, Tiret L, Smieja M, Cambien F, Meyer J, Lackner KJ; AtheroGene Investigators. 2003. Glutathione peroxidase 1 activity and cardiovascular events in patients with coronary artery disease. $N$ Engl J Med 349: 1605-1613.

34) Akkus I, Saglam NI, Caglayan O, Vural H, Kalak S, Saglam M. 1996. Investigation of erythrocyte membrane lipid peroxidation and antioxidant defense systems of patients with coronary artery disease (CAD) documented by angiography. Clin Chim Acta 244: 173-180.

35) Yegin A, Yegin H, Aliciguzel Y, Deger N, Semiz E. 1997. Erythrocyte selenium-glutathione peroxidase activity is lower in patients with coronary atherosclerosis. Jpn Heart J 38: 793-798.

36) Kloner RA, Przyklenk K, Whittaker P. 1989. Deleterious effects of oxygen radicals in ischemia/reperfusion. Resolved and unresolved issues. Circulation 80: 11151127.

37) Singh RB, Niaz MA, Sharma JP, Kumar R, Bishnoi I, Begom R. 1994. Plasma levels of antioxidant vitamins and oxidative stress in patients with acute myocardial infarction. Acta Cardiol 49: 441-452.

38) Esterbauer H, Gebicki J, Puhl H, Jurgens G. 1992. The role of lipid peroxidation and antioxidants in oxidative modification of LDL. Free Radic Biol Med 13: 341-390.

39) Baker TA, Milstien S, Katusic ZS. 2001. Effect of vitamin $\mathrm{C}$ on the availability of tetrahydrobiopterin in human 
endothelial cells. J Cardiovasc Pharmacol 37: 333-338.

40) Klipstein-Grobusch K, Geleijnse JM, den Breeijen JH, Boeing H, Hofman A, Grobbee DE, Witteman JC. 1999. Dietary antioxidants and risk of myocardial infarction in the elderly: the Rotterdam Study. Am J Clin Nutr 69: 261-266.

41) Nyyssonen K, Parviainen MT, Salonen R, Tuomilehto J, Salonen JT. 1997. Vitamin C deficiency and risk of myocardial infarction: prospective population study of men from eastern Finland. BMJ 314: 634-638.

42) Singh RB, Ghosh S, Niaz MA, Singh R, Beegum R, Chibo H, Shoumin Z, Postiglione A. 1995. Dietary intake, plasma levels of antioxidant vitamins, and oxidative stress in relation to coronary artery disease in elderly subjects. Am J Cardiol 76: 1233-1238.

43) Gaziano TA. 2005. Cardiovascular disease in the developing world and its cost-effective management. Circulation 112: 3547-3553.

44) Chrysohoou C, Panagiotakos DB, Pitsavos C, Skoumas J, Economou M, Papadimitriou L, Stefanadis C. 2007. The association between pre-hypertension status and oxidative stress markers related to atherosclerotic disease: the
ATTICA study. Atherosclerosis 192: 169-176.

45) Keaney JF Jr, Larson MG, Vasan RS, Wilson PW, Lipinska I, Corey D, Massaro JM, Sutherland P, Vita JA, Benjamin EJ. 2003. Obesity and systemic oxidative stress: clinical correlates of oxidative stress in the Framingham Study. Arterioscler Thromb Vasc Biol 23: 434-439.

46) Chiabrando C, Avanzini F, Rivalta C, Colombo F, Fanelli R, Palumbo G, Roncaglioni MC; PPP Collaborative Group on the antioxidant effect of vitamin E. 2002. Long-term vitamin E supplementation fails to reduce lipid peroxidation in people at cardiovascular risk: analysis of underlying factors. Curr Control Trials Cardiovasc Med 3: 5.

47) Stocker R, Keaney JF Jr. 2004. Role of oxidative modifications in atherosclerosis. Physiol Rev 84: 1381-1478.

48) Morel DW, Hessler JR, Chisolm GM. 1983. Low density lipoprotein cytotoxicity induced by free radical peroxidation of lipid. J Lipid Res 24: 1070-1076.

49) Dubois-Randé JL, Artigou JY, Darmon JY, Habbal R, Manuel C, Tayarani I, Castaigne A, Grosgogeat Y. 1994. Oxidative stress in patients with unstable angina. Eur Heart J 15: 179-183. 